\title{
Differentiation of Human Breast-Milk Stem Cells to Neural Stem Cells and Neurons
}

\author{
Seyed Mojtaba Hosseini, ${ }^{1,2,3}$ Tahere Talaei-khozani, ${ }^{4}$ \\ Mahsa Sani, ${ }^{1,2,3}$ and Bahareh Owrangi ${ }^{1,2}$ \\ ${ }^{1}$ Student Research Committee, Shiraz University of Medical Sciences, Shiraz, Iran \\ ${ }^{2}$ Cell and Molecular Student Research Group, Medical Faculty, Shiraz University of Medical Sciences, Shiraz, Iran \\ ${ }^{3}$ Stem Cell Laboratory, Department of Anatomy, Shiraz University of Medical Sciences, Shiraz, Iran \\ ${ }^{4}$ Department of Anatomy, Shiraz University of Medical Sciences, Shiraz, Iran
}

Correspondence should be addressed to Seyed Mojtaba Hosseini; hoseini2010m@gmail.com

Received 7 July 2014; Revised 8 October 2014; Accepted 20 October 2014; Published 25 November 2014

Academic Editor: Changiz Geula

Copyright (c) 2014 Seyed Mojtaba Hosseini et al. This is an open access article distributed under the Creative Commons Attribution License, which permits unrestricted use, distribution, and reproduction in any medium, provided the original work is properly cited.

Objectives. Human breast milk contains a heterogeneous population of cells that have the potential to provide a noninvasive source of cells for cell therapy in many neurodegenerative diseases without any ethical concern. The objectives of this study were to differentiate the breast milk-derived stem cells (BMDSC) toward neural stem cells and then into the neurons and neuroglia. Materials and Methods. To do this, the BMDSC were isolated from human breast milk and cultured in Dulbecco's modified Eagle medium/F12 (DMEM/F12) containing fibroblast growth factor (bFGF). The cells were then characterized by evaluation of the embryonic and stem cell markers. Then, the cells were exposed to culture medium containing 1\% B27 and 2\% N2 for 7-10 days followed by medium supplemented with B27, N2, bFGF $10 \mu \mathrm{g} / \mathrm{mL}$, and endothelial growth factor (EGF) $20 \mu \mathrm{g} / \mathrm{mL}$. Then, the sphereforming assay was performed. The spheres were then differentiated into three neural lineages by withdrawing growth factor in the presence of 5\% FBS (fetal bovine serum). The immunofluorescence was done for $\beta$-tubulin III, O4, and GFAP (glial fibrillary acidic protein). Results. The results indicated that the cells expressed both embryonic and mesenchymal stem cell (MSC) markers. They also showed neurospheres formation that was nestin-positive. The cells were also differentiated into all three neural lineages. Conclusion. The BMDSC can behave in the same way with neural stem cells. They were differentiated into oligodendrocytes, and astrocytes as well as neurons.

\section{Introduction}

Increase in the prevalence of neurodegenerative diseases and neural damage has caused the scientists to search for various approaches such as cell therapy to improve the neurogenesis techniques [1]. A lot of investigations confirmed the presence of adult stem cells in various tissues including breast milk [2]. Breast milk contains a heterogeneous cell population; besides, a subpopulation with stem cell properties including the ability to be differentiated into different cell lineages has been isolated from fresh human milk $[2,3]$. A bipotential stem cell with the differentiation capacity into mammary epithelial cell and myoepithelial cells has been detected in mammary gland tissue [4]. Maternal mammary stem cells have been considered as one of the cell sources in breast milk [5]. The presence of exfoliated epithelial cells from alveoli, macrophages, and lymphocytes was also reported $[6,7]$. It has been also reported that $10-15 \%$ of the cells isolated from fresh breast milk expressed mesenchymal stem cell (MSC) markers and culturing the isolated cells led to an increase in the MSC population due to their higher capacity of cell proliferation [2]. The presence of a nestin-positive subpopulation was also reported in the breast milk-derived cells; however, the frequency of these cells was low $[8,9]$. 
Previous studies identified the presence of activated mammary stem cell (MaSC) in breast milk through staining cells for MaSC markers [2]. Hassiotou et al. named these cells as human breast-milk stem cells (hBSCs) [3]. Their results demonstrated that these stem cells have a capability to be differentiated into mammary cells (luminal and myoepithelial). Furthermore, they determined the expression of a group of embryonic stem cell- (ESC-) associated genes such as OCT4, KLF4, NANOG, and SOX2 in hBSCs [3]. Also, it has been reported that the phenotype, colony morphology, and differentiating capability of hBSCs are similar to those in $\operatorname{ESC}[3,10]$. Consequently, as breast milk contains these special pluripotent stem cells, it can be utilized as a valuable and a new easily available source for regenerative medicine $[3,10]$. The presence of nestin-positive cell population and also a subpopulation of expressed ESC markers in breast milk caused this noninvasive source of stem cells to be considered as a good candidate for differentiation into neural cell lineage [10].

Both mammary gland and nervous system have the same origin. It has been demonstrated that the common regulators play role in the development of both mammary gland and neuroepithelium, and these regulators are also involved in ESCs differentiation and self-renewal [11]. These common embryonic origins and also common regulators may suggest breast milk-derived cells as a good source for neural cell lineages differentiation.

Previous studies reported that neural stem cells showed the capability to be differentiated toward neuronal cells $[12$, 13]. They may be considered as an appropriate source for cell replacement therapies (CRTs) of the brain diseases [14]. However, there have been various reports which show the risks of neural stem cell application for the patients including tumor formation, insufficient migration, immune rejection, surgical threats, and transmission of infections possibility during transplantation [15]. Besides, neural stem cell isolation is invasive. Therefore, finding an alternative stem cell source is essential to overcome such issues and barriers.

The pluripotency of the breast milk-derived cells was evaluated by exposing the cells to various culture conditions. The cells treated with neurogenic medium expressed nestin and tubulin which indicated the cell differentiation into neural progenitor cell and neuron-like cells, respectively [3]. This study tried to find the breast milk-derived cell ability to be differentiated into three neural cell lineages, neurons, astrocytes, and oligodendrocytes. Also, the current study showed that the breast milk-derived cell behaved in a similar way to neural stem cells in vitro.

\section{Materials and Methods}

2.1. Sample Collection. This study was approved by the Ethics Committee of Shiraz University of Medical Sciences, and all participants provided informed written consent. Women, who were healthy breastfeeding participants, submitted informed written consent prior to sample collection. In aseptic procedures, mature breast milk $(5-200 \mathrm{~mL})$ samples were collected from them and instantly transferred to the stem cell laboratory.

2.2. Isolation of Cells from Breast Milk Sample. Disinfected phosphate buffered saline (PBS) (pH 7.4, Gibco) equal volumes were used to dilute the breast milk and they were centrifuged for 20 minutes at $20^{\circ} \mathrm{C}$ at $805 \mathrm{~g}$. Then, skim milk liquid component and fat layer were taken out. In PBS, the cell pellet, the remaining part, was washed three times. After that, the cell pellet was resuspended in $10 \%$ fetal bovine serum (FBS, Certified, Invitrogen) within PBS (blocking buffer). To determine each sample's cell viability and cell concentration, the Neubauer hemocytometer was utilized with Trypan Blue for segregation.

2.3. Culture of the Isolated Cells. Breast milk cells (40000 cells $/ \mathrm{mL}$ ) were cultured in plates coated with gelatin. They were incubated at $5 \% \mathrm{CO}_{2}$ and $37^{\circ} \mathrm{C}$; also, the media were changed daily. After 5 days of culturing, each colony was separately selected and relocated in new dishes and cultured in medium in order to make feeder culture of the second and third ones. Furthermore, ultralow binding plates were used to seed cells on them to have spheroid culture and the ES media (DMEM/F12, KOSR (knockout serum replacement) 10\%, nonessential amino acid $1 \%$, bFGF $10 \mu \mathrm{g} / \mathrm{mL}$, and pen/strep $1 \%)$ were added to the plates. Whenever the cells needed to be passaged, they were trypsinized (Gibco) at $37^{\circ} \mathrm{C}$ in 5 minutes and were divided to $1: 2$.

2.4. Immunocytochemistry for the Breast Milk-Derived Stem Cells. Some embryonic and mesenchymal stem cell markers antibodies such as Nanog, OCT4 (Abcam ab19857 1:500), SOX2, CD44 (Abcam ab119863 1:500), CD105 (Abcam ab44967 1:250), CD106 (Abcam ab19569 1:500), CD90 (Abcam ab225 1:250), and CD133 (Millipore MAB4399) were used to characterize the isolated cells from human breast milk by immunocytochemistry method. Briefly, the cultured cells were fixed by paraformaldehyde $4 \%$ in $4^{\circ} \mathrm{C}$ for 20 minutes; after washing with PBS, primary antibodies were diluted in PBS containing $0.3 \%$ triton and $5 \%$ goat serum and the samples were kept in room temperature for 60 minutes. After that, washing with PBS was performed for 3 times. Then secondary antibodies were added and, after 45 minutes of incubation in room temperature, the last washing with PBS was done.

2.5. Differentiation into Neural Stem Cell. The isolated cells were cultured in gelatin coated plates with concentration of 10000 cells $/ \mathrm{cm}^{2}$ with DMEM/F12, 1\% B27, and 2\% N2 for 7-10 days. After this period of time, some sphere-like cell aggregations were seen. These spheres were separated and passaged in a different plate using DMEM/F12 containing B27, N2, bFGF $10 \mu \mathrm{g} / \mathrm{mL}$, and EGF $20 \mu \mathrm{g} / \mathrm{mL}$ (NS-A media).

2.6. Sphere-Forming Assay. The differentiated cells were cultured in appropriate media (NS-A media). The media were removed every 3-5 days and changed with the fresh ones. The cells were incubated in $5 \% \mathrm{CO}_{2}$ at $37^{\circ} \mathrm{C}$ for 7 days. 
TABLE 1: The percentage and SD of the cells that expressed various stem cell markers.

\begin{tabular}{|c|c|c|c|c|c|c|c|c|}
\hline CD44 & CD105 & CD90 & CD106 & SOX2 & Nanog & OCT $4 / 3$ & Nestin & CD133 \\
\hline $67 \% \pm 10.7$ & $68.3 \% \pm 3.91$ & $19.7 \% \pm 3.74$ & $8.4 \% \pm 2.36$ & $57.3 \% \pm 7.74$ & $66.2 \% \pm 6.52$ & $42.9 \% \pm 6.99$ & $7.4 \% \pm 3.30$ & $2.76 \% \pm 1.93$ \\
\hline
\end{tabular}

Then, the spheres were formed and each cell of these spheres was capable of providing another sphere by passaging. For neural stem cells identification, immunocytochemistry was performed for nestin antibody (Millipore, AB5922) on neurospheres and CD133 (Millipore MAB4399) [16] for neural stem cells with protocol mentioned above.

2.7. Neural Stem Cell Differentiation. Neural stem cells (NSCs) $(5000$ cells $/ \mathrm{mL})$ were seeded in poly-L-ornithinecoated culture dishes to be differentiated into neuron, oligodendrocyte, and astrocyte. For differentiation, bFGF and EGF were removed from the media and FCS 5\% was added to them and after 5 days the differentiated neural stem cells provided neurons, oligodendrocytes, and astrocytes. For neuron, oligodendrocyte, and astrocyte detection, antibodies, $\beta$-tubulin III (Promega G7121, 1:2000), O4 [17] (Millipore, MAB345 1:50), and GFAP [18] (DakoCytomation, Code number Z0334 1:500), respectively, were assessed by an immunocytochemistry method similar to the one previously described.

2.8. 4',6-Diamino-2-phenylindole Dihydrochloride (DAPI) Staining. To detect the cells' nucleus, they were fixed with paraformaldehyde $4 \%$ and then $4^{\prime}, 6$-diamino-2-phenylindole dihydrochloride (Millipore S7113 1:1000) was added to the fixed cells and they were kept in room temperature for 30 minutes.

\section{Results}

3.1. Breast-Milk Stem Cell Isolation and Characterization. The isolated breast-milk-derived cells were adherent to the plates and their morphology was similar to the cells of myoepithelium of the breast (Figure 1). They were cultured to the 10th passage and after each passage the provided cells were capable of proliferating and kept their expansion potential.

The immunohistochemistry staining showed a subpopulation of breast milk-derived cells that expressed embryonic stem cells markers such as Nanog $(66.2 \% \pm 6.52)$, OCT4 $(42.9 \% \pm 6.99)$, and Sox $2(57.3 \% \pm 7.74)$ (Figure 2). A subpopulation of the isolated cells also expressed markers that were also detected on the surface of mesenchymal stem cells including CD44 (67\% \pm 10.7$), \mathrm{CD} 105(68.3 \% \pm 3.91), \mathrm{CD} 106$ $(8.4 \% \pm 2.36)$, and CD133 (2.76\% \pm 1.93$)$. Table 1 summarizes the frequency of the positive cell for each marker.

3.2. The Neural Stem Cells Differentiated from Breast MilkDerived Cells. After exposing the breast-milk stem cells to NS-A media (DMEM/F12, N2, B27, bFGF, and EGF) for 5 days, they formed shiny, floating, sphere-like cell aggregations, neurospheres, measuring about $100 \mu \mathrm{m}$ in diameter (Figure 3). The enzymatically dissociated neurospheres

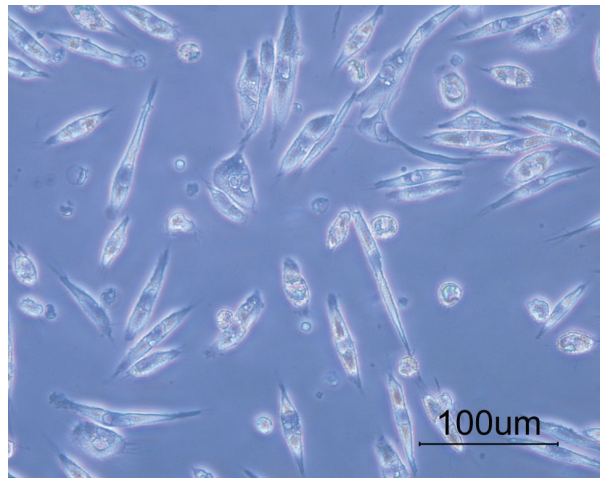

FIGURE 1: The breast milk-derived cells showed a fusiform morphology with few processes.

showed the capability of forming a new sphere within 5-7 days. In addition, the cells kept their sphere-forming ability till the 8th passage without any significant change in their sphere-forming frequency (Figure 8).

A small subpopulation of the breast milk-derived cells expressed nestin $(7.4 \% \pm 3.30)$ and $\mathrm{CD} 133(2.76 \% \pm 1.93)$ as markers for neural stem cells. The frequency of the nestinpositive $(58.20 \% \pm 6.71)$ (Figures 6 and 9) and CD133positive $(58.74 \% \pm 3.36)$ (Figures 7 and 10$)$ cells was increased significantly after exposing the cells to neurogenic media and neurosphere formation. The behavior of the nestin-positive breast milk-derived cells treated with neurogenic media, including the formation of spheroid aggregates, was similar to the neural stem cells. Therefore, they may be neural stem cell-like cells.

3.3. Capability of Producing Three Neural Lineages. The most important characteristic for specification of neural stem cells is their ability to produce three neural lineages consisting of neurons, oligodendrocytes, and astrocytes. Differentiated neurons showed two processes extended from cell body. The cells with branched intricate processes extended from cell body represented oligodendrocytes. Differentiated astrocytes showed a flat or polygonal cell body with several processes.

After adding 5\% fetal bovine serum, removing growth factors (bFGF and EGF), to the cells for 5 days, the neural stem cell-like cells proliferated and attached to the plate totally and their appearances were completely changed into three neural cell lineages (Figure 4).

To detect neurons, the expression of neuronal marker, $\beta$ tubulin III, was evaluated. The percentage of the tubulin III was $19 \% \pm 2.44$ of the cells treated with neurogenic media. For detection of oligodendrocyte, anti-O4 antibody [17] was used and the frequency of the O4-positive cells was $14.31 \% \pm$ 2.31; and for detection of astrocytes, anti-GFAP antibody [18] 


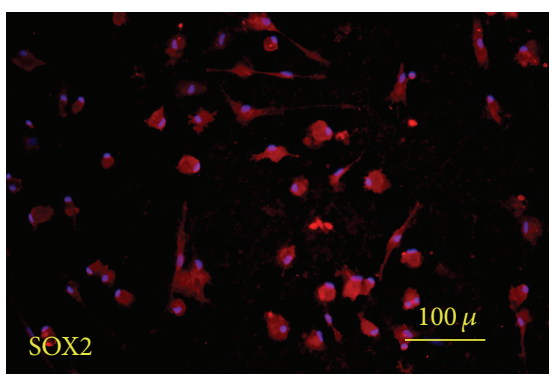

(a)

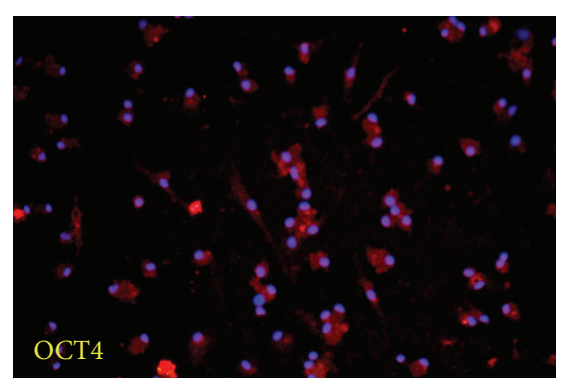

(b)

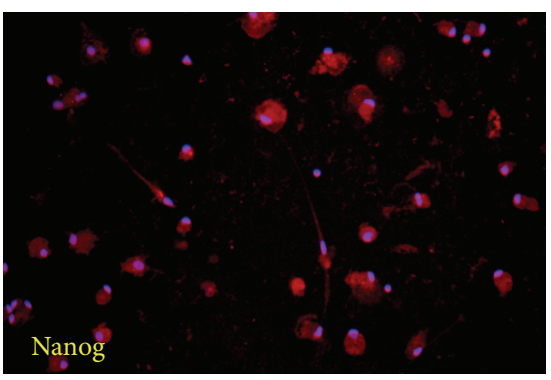

(c)

FIGURE 2: The immunofluorescence of the cells showed that a subpopulation of the breast milk-derived cells reacted for OCT4, Nanog, and SOX2 antibodies.

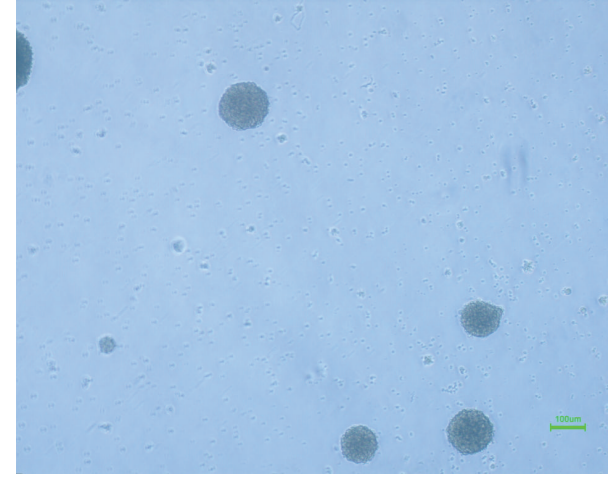

FIGURE 3: Neurospheres, formed after exposing the breast milkderived cells to neurogenic medium.

TABLE 2: The percentage of $\beta$-tubulin, O4, and GFAP.

\begin{tabular}{lcc}
\hline$\beta$-Tubulin III & O4 & GFAP \\
\hline $19 \% \pm 2.44$ & $14.31 \% \pm 2.31$ & $66.69 \% \pm 7.50$
\end{tabular}

was administrated and it was shown that $66.69 \% \pm 7.50$ of the cells were astrocytes (Figure 5, Table 2).

\section{Discussion}

The presence of the cells with various origins was detected in human breast milk. Therefore, breast milk cells have been suggested to be used for treating neonatal disorders [19]. Breast-milk stem cells have been previously demonstrated to express nestin, a neuroectoderm marker; however, a few samples contained the cells expressing neurofilament, a late neural differentiation marker. However, the frequency of the nestin-positive cells was low [8]. The presence of nestinpositive cells indicated that the breast-milk stem cells can be an appropriate candidate for differentiation toward neurons or neuroglia. The results of the current study revealed that the exposure of the whole cell population of breast milk to neurogenic medium led to an increase in the presence of nestin-positive cells and that the cell behavior in neurosphere formation is the same as what happened in the culture of neural stem cells [20].

Further differentiation of nestin-positive cells into the neuron as well as neuroglia was shown in this study as indicated by the presence of cells that expressed $\beta$-tubulin as neuron marker, $\mathrm{O} 4$ as oligodendrocyte marker, and GFAP as astrocyte marker. Several studies also showed that nestinpositive cells were derived from the neurosphere of the neural stem cells isolated from the avian species [21], mouse embryo [22], adult mouse [23], and human [24] and differentiated into three neural lineages. It seems that the cells derived from breast milk were differentiated in the same way as in the case of neural stem cells.

Mesenchymal stem cells derived from human adipose tissue [25, 26], bone marrow [26], muscle [27], and umbilical cord [28] have been shown to be able to be differentiated toward neuron-like cells. Neuron-like cells differentiated from Wharton jelly of the umbilical cord were also transplanted to the A $\beta \mathrm{PP} / \mathrm{PS} 1$ mouse. The transplantation improved the cognitive reactions of the mouse and decreased the level of amyloid $\beta$-peptides deposition [29]. Human umbilical mesenchymal stem cells-derived neurospheres with BDNF were transplanted to the injured spinal cord and the morphologic and functional recoveries have been demonstrated [30]. These data indicated that nonneural stem cells may be functional when they were transplanted to the animal models. Therefore, the neural-like cells or neuroglia derived from breast milk also may be as effective as those derived from the other sources; however, it needs further investigations.

Our results indicated that breast milk-derived stem cells express embryonic cell markers such as Nanog, OCT4, Sox2, SEEA4, and TRA 1-60/81. The expression of some mesenchymal stem cell markers has been shown previously [19]. It indicated that these cells may behave like both embryonic and mesenchymal stem cells. Embryonic stem cells have a great potential to be differentiated toward neural cell lineages $[31,32]$. They can be differentiated into neural progenitor cells spontaneously $[33,34]$. The stability in electrical phenotype of stem cell-derived neuron has been shown previously [35], revealing that the differentiated cells may be functional. The transplanted Mesenchymal stem cells in CNS has been shown they are capable to survive and differentiate to neural 

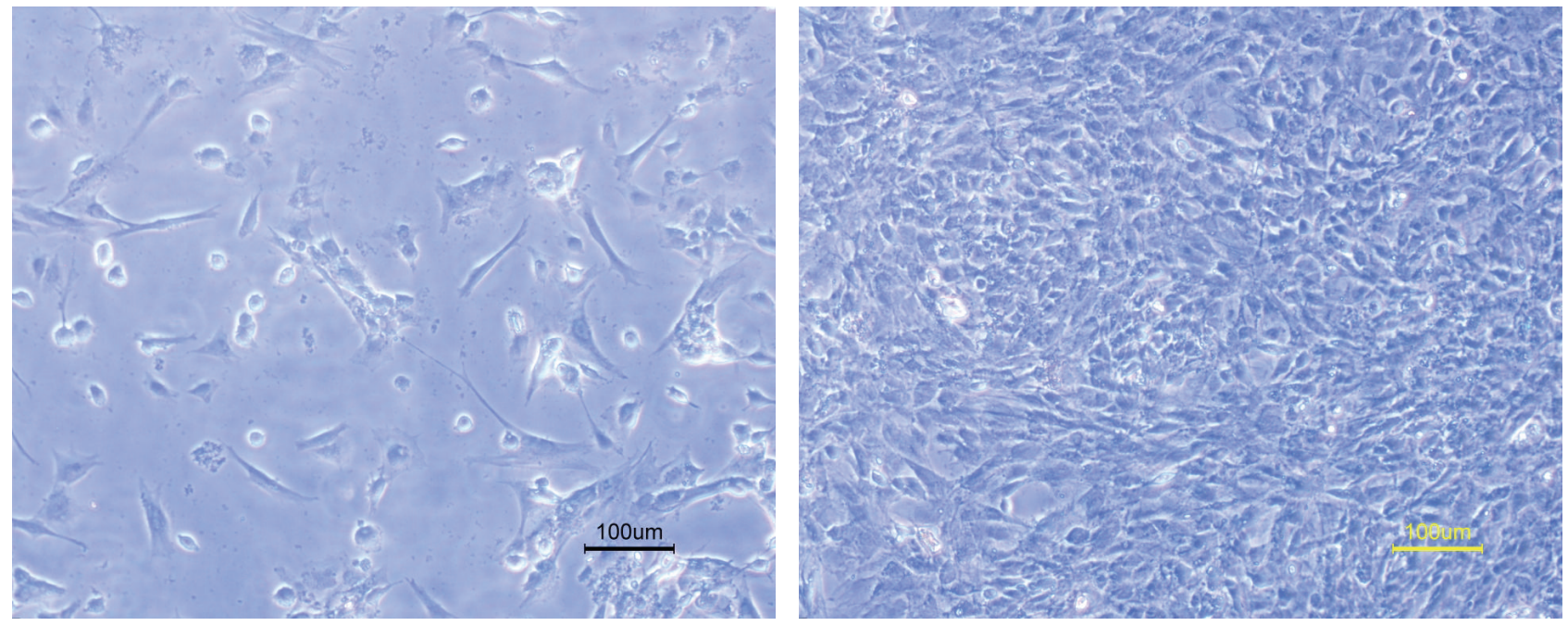

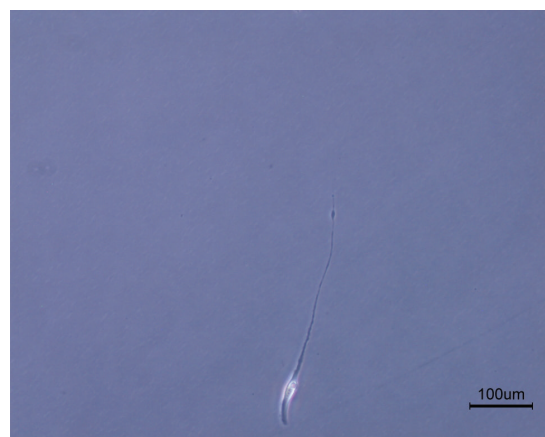

(a) Neuron

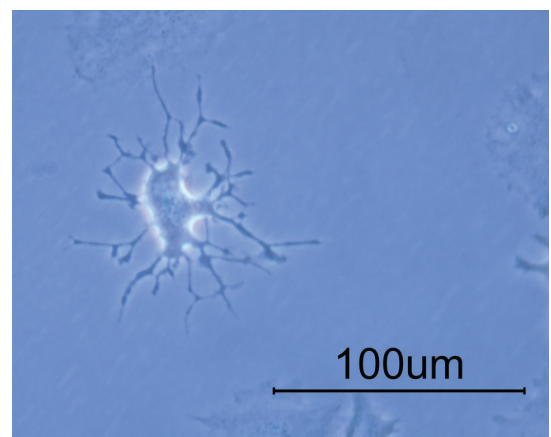

(b) Oligodendrocyte

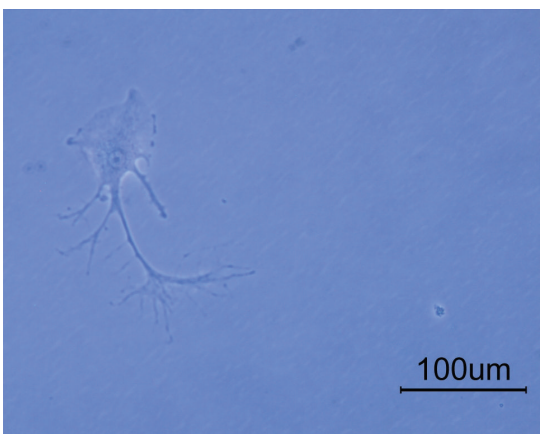

(c) Astrocyte

FIGURE 4: Inverted microscopy of the breast milk-derived cells differentiated toward three neural cell lineages.

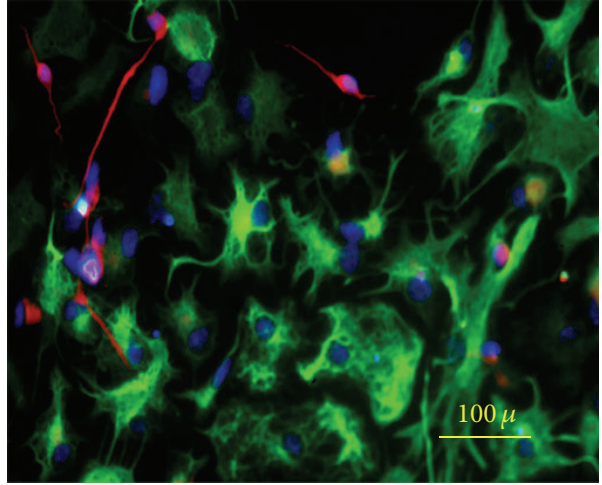

(a)

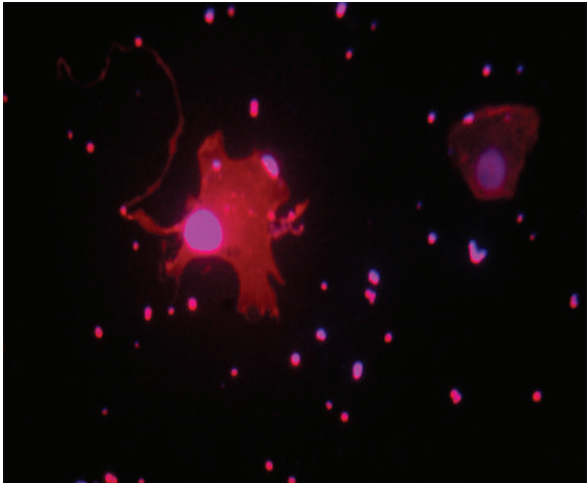

(b)

Figure 5: (a) Neurons and astrocytes differentiated from breast milk stem cells-derived neural stem cell stained with anti- $\beta$-tubulin-Alexa Flour 568 (red) and anti-GFAP-Alexa Flour 488 (green); (b) oligodendrocyte differentiated from breast milk stem cell-derived neural stem cell stained with anti-O4-Alexa Flour 568.

lineages [36]. The breast milk-derived stem cells showed the capability to be differentiated into neural cell lineages and their similarity to both embryonic and mesenchymal stem cells makes them a good candidate for cell therapy in neurodegenerative diseases.

\section{Conclusion}

As the isolation of neural stem cells is an invasive procedure, using breast milk-derived cells as a source of cell therapy may be preferable especially for the patients in child-bearing 


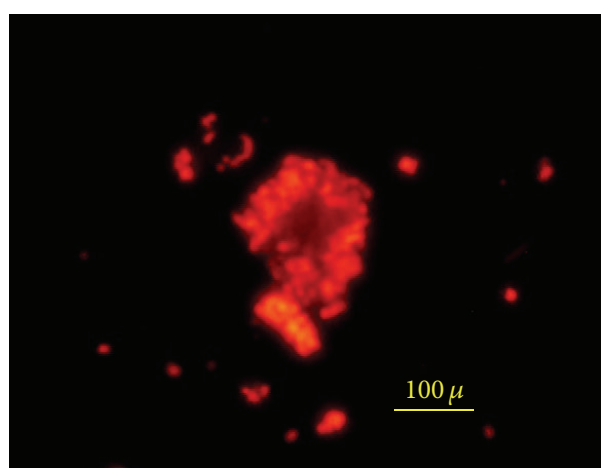

(a)

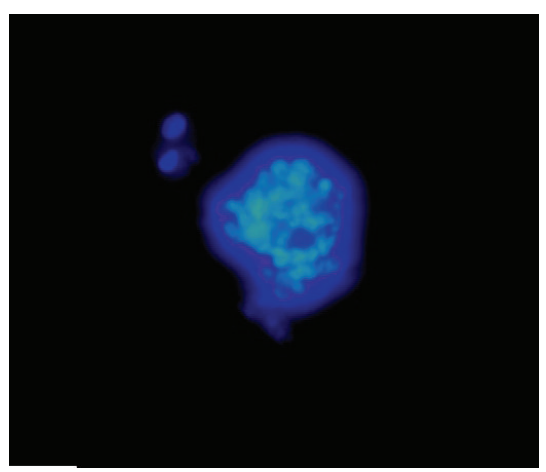

(b)

FIGURE 6: A neurosphere stained with anti-nestin-Alexa Flour 568 (red) antibody (a) and DAPI (b).

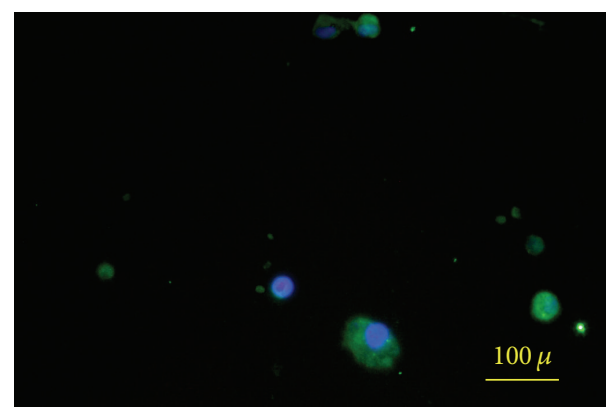

FIGURE 7: Neural stem cell stained with CD133 and DAPI.

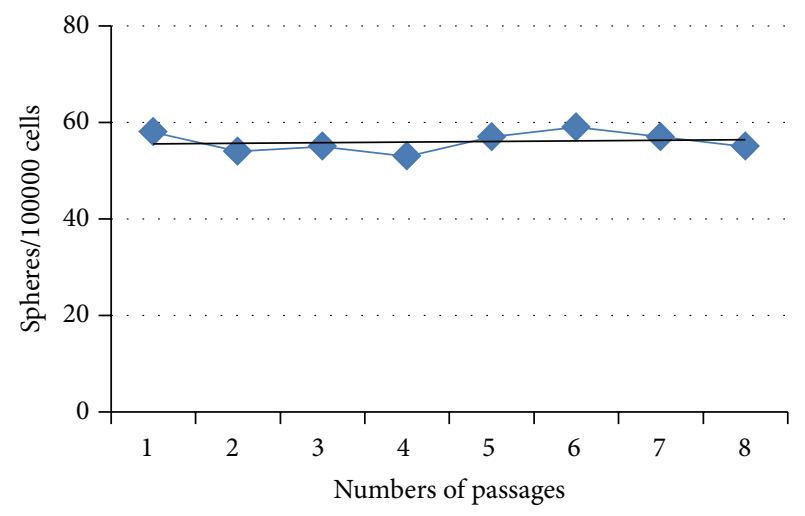

FIGURE 8: Sphere frequency assay.

ages. However, the physiological test and also in vivo studies should be done to ensure that the cells do not dedifferentiate and are functional when they are transplanted.

\section{Abbreviations}

GFAP: Glial fibrillary acidic protein

MSC: Mesenchymal stem cell

bFGF: Basic fibroblast growth factor

BMDSC: Breast milk-derived stem cells

EGF: Epidermal growth factor

Masc: Mammary gland stem cell

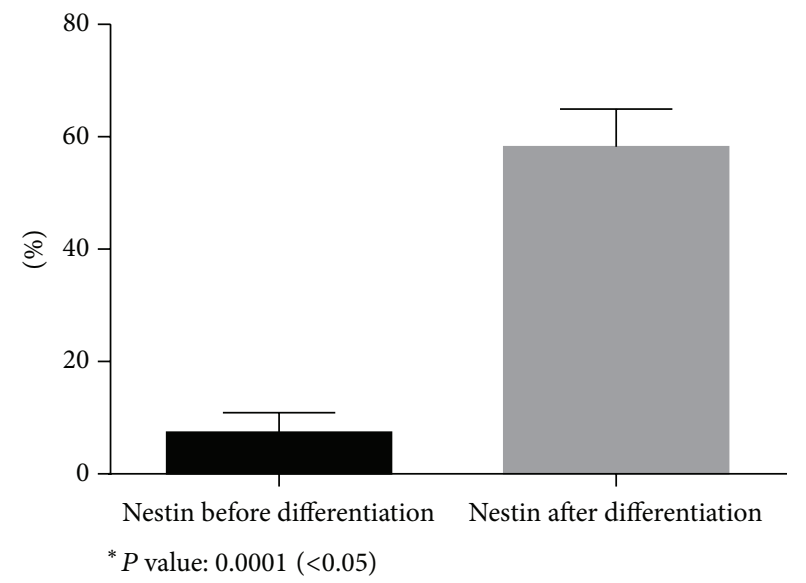

Figure 9: Comparison of nestin expression before differentiation and after differentiation.

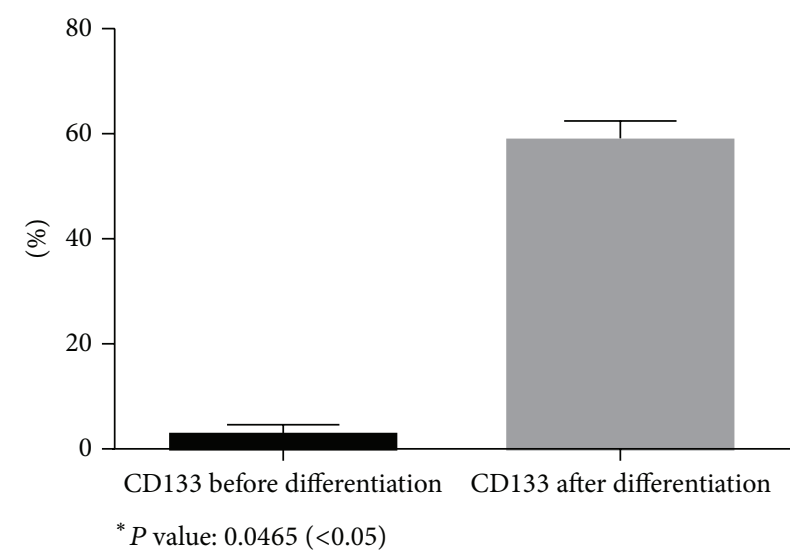

FIgURE 10: Comparison of CD133 expression before differentiation and after differentiation.

CNS: Central nervous system

ESC: Embryonic stem cell

CRT: Cell replacement therapy

hBSCs: Human breast-milk stem cells

iPSC: Induced pluripotent stem cell 
NSC: Neural stem cell

FBS: Fetal bovine serum.

\section{Conflict of Interests}

The authors of this paper report no conflict of interests.

\section{Acknowledgment}

The authors wish to thank the research deputy of Shiraz University of Medical Sciences for offering Grant no. 7534.

\section{References}

[1] T. H. Mouhieddine, F. H. Kobeissy, M. Itani, A. Nokkari, and K. K. Wang, "Stem cells in neuroinjury and neurodegenerative disorders: challenges and future neurotherapeutic prospects," Neural Regeneration Research, vol. 9, no. 9, pp. 901-906, 2014.

[2] S. Patki, S. Kadam, V. Chandra, and R. Bhonde, "Human breast milk is a rich source of multipotent mesenchymal stem cells," Human Cell, vol. 23, no. 2, pp. 35-40, 2010.

[3] F. Hassiotou, A. Beltran, E. Chetwynd et al., "Breastmilk is a novel source of stem cells with multilineage differentiation potential," Stem Cells, vol. 30, no. 10, pp. 2164-2174, 2012.

[4] G. Dontu, M. Al-Hajj, W. M. Abdallah, M. F. Clarke, and M. S. Wicha, "Stem cells in normal breast development and breast cancer," Cell Proliferation, Supplement, vol. 36, no. 1, pp. 59-72, 2003.

[5] P. Dutta and W. J. Burlingham, "Stem cell microchimerism and tolerance to non-inherited maternal antigens," Chimerism, vol. 1, no. 1, pp. 2-10, 2010.

[6] O. Ballard and A. L. Morrow, "Human Milk Composition: nutrients and bioactive Factors," Pediatric Clinics of North America, vol. 60, no. 1, pp. 49-74, 2013.

[7] F. C. S. Ho, R. L. C. Wong, and J. W. M. Lawton, "Human colostral and breast milk cells. A light and electron microscopic study," Acta Paediatrica Scandinavica, vol. 68, no. 3, pp. 389396, 1979.

[8] Y. Fan, Y. S. Chong, M. A. Choolani, M. D. Cregan, and J. K. Y. Chan, "Unravelling the mystery of stem/progenitor cells in human breast milk," PLoS ONE, vol. 5, no. 12, Article ID e14421, 2010.

[9] M. D. Cregan, Y. Fan, A. Appelbee et al., "Identification of nestin-positive putative mammary stem cells in human breastmilk," Cell and Tissue Research, vol. 329, no. 1, pp. 129-136, 2007.

[10] A.-J. Twigger, S. Hodgetts, L. Filgueira, P. E. Hartmann, and F. Hassiotou, "From breast milk to brains: the potential of stem cells in human milk," Journal of Human Lactation, vol. 29, no. 2, pp. 136-139, 2013.

[11] T. Esmailpour and T. Huang, "TBX3 promotes human embryonic stem cell proliferation and neuroepithelial differentiation in a differentiation stage-dependent manner," Stem Cells, vol. 30, no. 10, pp. 2152-2163, 2012.

[12] H. Guerrero-Cazares, O. Gonzalez-Perez, M. Soriano-Navarro, G. Zamora-Berridi, J. M. Garcia-Verdugo, and A. QuinonesHinojosa, "Cytoarchitecture of the lateral ganglionic eminence and rostral extension of the lateral ventricle in the human fetal brain," Journal of Comparative Neurology, vol. 519, no. 6, pp. 1165-1180, 2011.
[13] N. Sanai, T. Nguyen, R. A. Ihrie et al., "Corridors of migrating neurons in the human brain and their decline during infancy," Nature, vol. 478, no. 7369, pp. 382-386, 2011.

[14] Y. Mu and F. H. Gage, "Adult hippocampal neurogenesis and its role in Alzheimer's disease," Molecular Neurodegeneration, vol. 6, no. 1, article 85, 2011

[15] R. Ramos-Zúñiga, O. González-Pérez, A. MacÍas-Ornelas, V. Capilla-González, and A. Quiñones-Hinojosa, "Ethical implications in the use of embryonic and adult neural stem cells," Stem Cells International, vol. 2012, Article ID 470949, 7 pages, 2012.

[16] Z. Ying, J. Gonzalez-Martinez, C. Tilelli, W. Bingaman, and I. Najm, "Expression of neural stem cell surface marker CD133 in balloon cells of human focal cortical dysplasia," Epilepsia, vol. 46, no. 11, pp. 1716-1723, 2005.

[17] L. E. DeWald, J. P. Rodriguez, and J. M. Levine, "The RE1 binding protein REST regulates oligodendrocyte differentiation," The Journal of Neuroscience, vol. 31, no. 9, pp. 3470-3483, 2011.

[18] J. L. Watson, T. J. Hala, R. Putatunda, D. Sannie, and A. C. Lepore, "Persistent at-level thermal hyperalgesia and tactile allodynia accompany chronic neuronal and astrocyte activation in superficial dorsal horn following Mouse Cervical Contusion Spinal Cord Injury," PLoS ONE, vol. 9, no. 9, Article ID e109099, 2014.

[19] S. Indumathi, M. Dhanasekaran, J. S. Rajkumar, and D. Sudarsanam, "Exploring the stem cell and non-stem cell constituents of human breast milk," Cytotechnology, vol. 65, no. 3, pp. 385-393, 2013.

[20] T. L. Walker and G. Kempermann, "One mouse, two cultures: isolation and culture of adult neural stem cells from the two neurogenic zones of individual mice," Journal of Visualized Experiments, no. 84, Article ID e51225, 2014.

[21] S. Dotan, A. Pinkas, T. A. Slotkin, and J. Yanai, "An avian model for the reversal of neurobehavioral teratogenicity with neural stem cells," Neurotoxicology and Teratology, vol. 32, no. 4, pp. 481-488, 2010.

[22] H. Azari, S. Sharififar, J. M. Fortin, and B. A. Reynolds, "The neuroblast assay: an assay for the generation and enrichment of neuronal progenitor cells from differentiating neural stem cell progeny using flow cytometry," Journal of Visualized Experiments, no. 62, Article ID e3712, 2012.

[23] H. Azari, G. W. Osborne, T. Yasuda et al., "Purification of immature neuronal cells from neural stem cell progeny," PLoS ONE, vol. 6, no. 6, Article ID e20941, 2011.

[24] M. Othman, C. Lu, K. Klueber, W. Winstead, and F. J. Roisen, "Clonal analysis of adult human olfactory neurosphere forming cells," Biotechnic and Histochemistry, vol. 80, no. 5-6, pp. 189200, 2005.

[25] C. Han, L. Song, Y. Liu, W. Zou, C. Jiang, and J. Liu, "Rat cortex and hippocampus-derived soluble factors for the induction of adipose-derived mesenchymal stem cells into neuron-like cells," Cell Biology International, vol. 38, no. 6, pp. 768-776, 2014.

[26] C. Han, L. Zhang, L. Song et al., "Human adipose-derived mesenchymal stem cells: a better cell source for nervous system regeneration," Chinese Medical Journal, vol. 127, no. 2, pp. 329337,2014

[27] E. B. Kwon, J. Y. Lee, S. Piao, I. G. Kim, J. C. Ra, and J. Y. Lee, "Comparison of human muscle-derived stem cells and human adipose-derived stem cells in neurogenic trans-differentiation," Korean Journal of Urology, vol. 52, no. 12, pp. 852-857, 2011. 
[28] E. Paldino, C. Cenciarelli, A. Giampaolo et al., "Induction of dopaminergic neurons From human Wharton's Jelly mesenchymal stem cell by forskolin," Journal of Cellular Physiology, vol. 229, no. 2, pp. 232-244, 2014.

[29] H. Yang, Z. Xie, L. Wei et al., "Human umbilical cord mesenchymal stem cell-derived neuron-like cells rescue memory deficits and reduce amyloid-beta deposition in an $\mathrm{A} \beta \mathrm{PP} / \mathrm{PS} 1$ transgenic mouse model," Stem Cell Research and Therapy, vol. 4, no. 4, article 76, 2013.

[30] L. Zhang, H.-T. Zhang, S.-Q. Hong, X. Ma, X.-D. Jiang, and R.-X. Xu, "Cografted wharton's jelly cells-derived neurospheres and BDNF promote functional recovery after rat spinal cord transection," Neurochemical Research, vol. 34, no. 11, pp. 20302039, 2009.

[31] M. Hatori, N. Shimozawa, L. Yasmin et al., "Role of retinoic acid and fibroblast growth factor 2 in neural differentiation from cynomolgus monkey (Macaca fascicularis) embryonic stem cells," Comparative Medicine, vol. 64, no. 2, pp. 140-147, 2014.

[32] J. Mong, L. Panman, Z. Alekseenko et al., "Transcription factorinduced lineage programming of noradrenaline and motor neurons from embryonic stem cells," Stem Cells, vol. 32, no. 3, pp. 609-622, 2014.

[33] G. Nistor, M. M. Siegenthaler, S. N. Poirier et al., "Derivation of high purity neuronal progenitors from human embryonic stem cells," PLoS ONE, vol. 6, no. 6, Article ID e20692, 2011.

[34] E. M. Vazey, M. Dottori, P. Jamshidi et al., "Comparison of transplant efficiency between spontaneously derived and noggin-primed human embryonic stem cell neural precursors in the quinolinic acid rat model of Huntington's disease," Cell Transplantation, vol. 19, no. 8, pp. 1055-1062, 2010.

[35] K. Needham, T. Hyakumura, N. Gunewardene, M. Dottori, and B. A. Nayagam, "Electrophysiological properties of neurosensory progenitors derived from human embryonic stem cells," Stem Cell Research, vol. 12, no. 1, pp. 241-249, 2014.

[36] M. Gutiérrez-Fernández, B. Rodríguez-Frutos, L. Otero-Ortega, J. Ramos-Cejudo, B. Fuentes, and E. Díez-Tejedor, "Adipose tissue-derived stem cells in stroke treatment: from bench to bedside," Discovery Medicine, vol. 16, no. 86, pp. 37-43, 2013. 


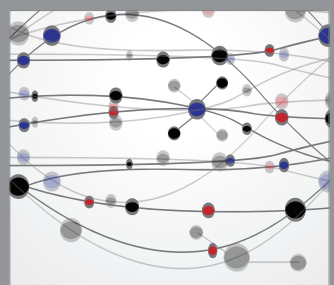

The Scientific World Journal
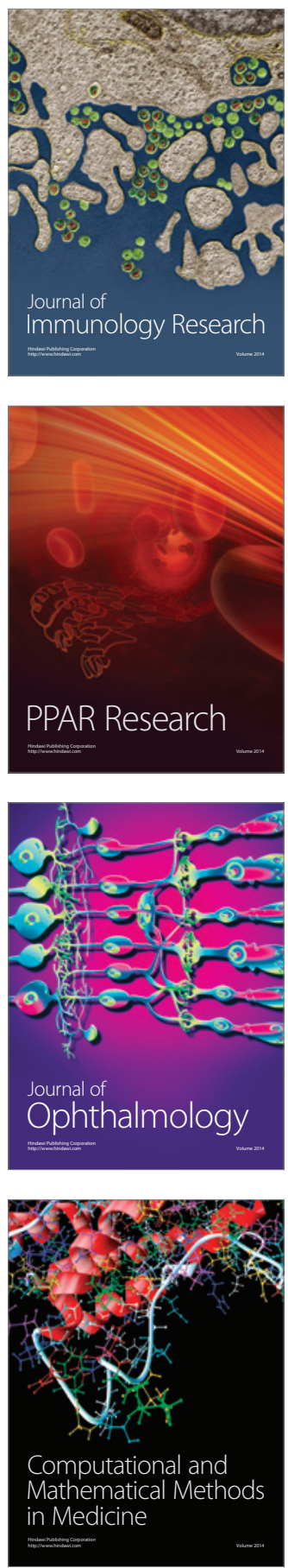

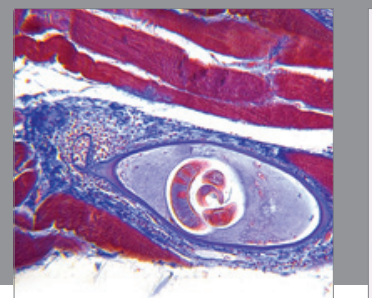

Gastroenterology

Research and Practice
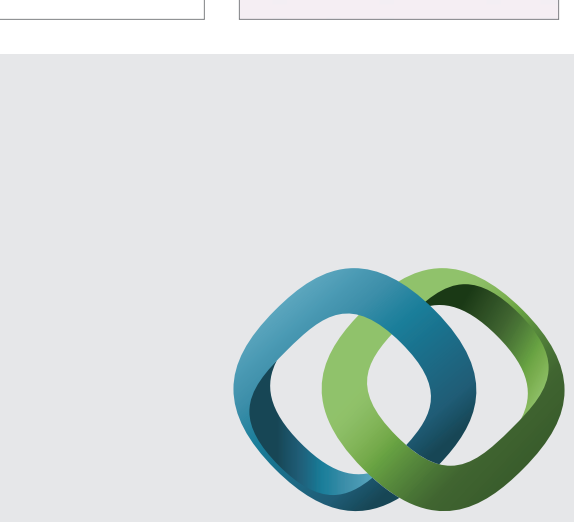

\section{Hindawi}

Submit your manuscripts at

http://www.hindawi.com
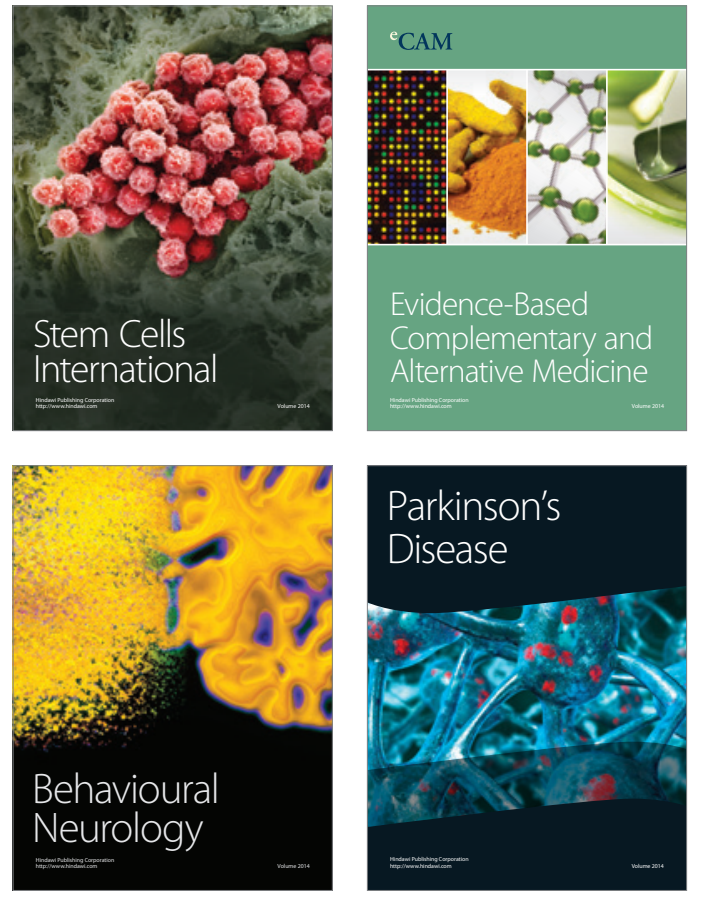
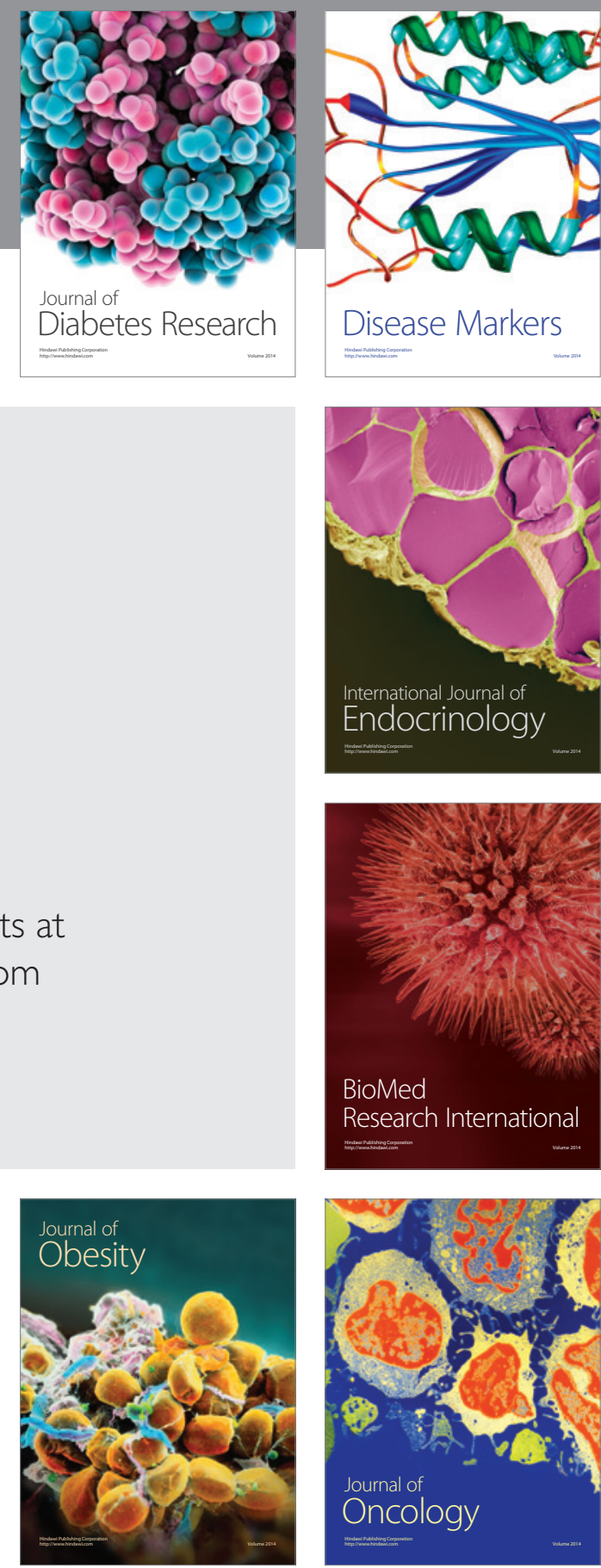

Disease Markers
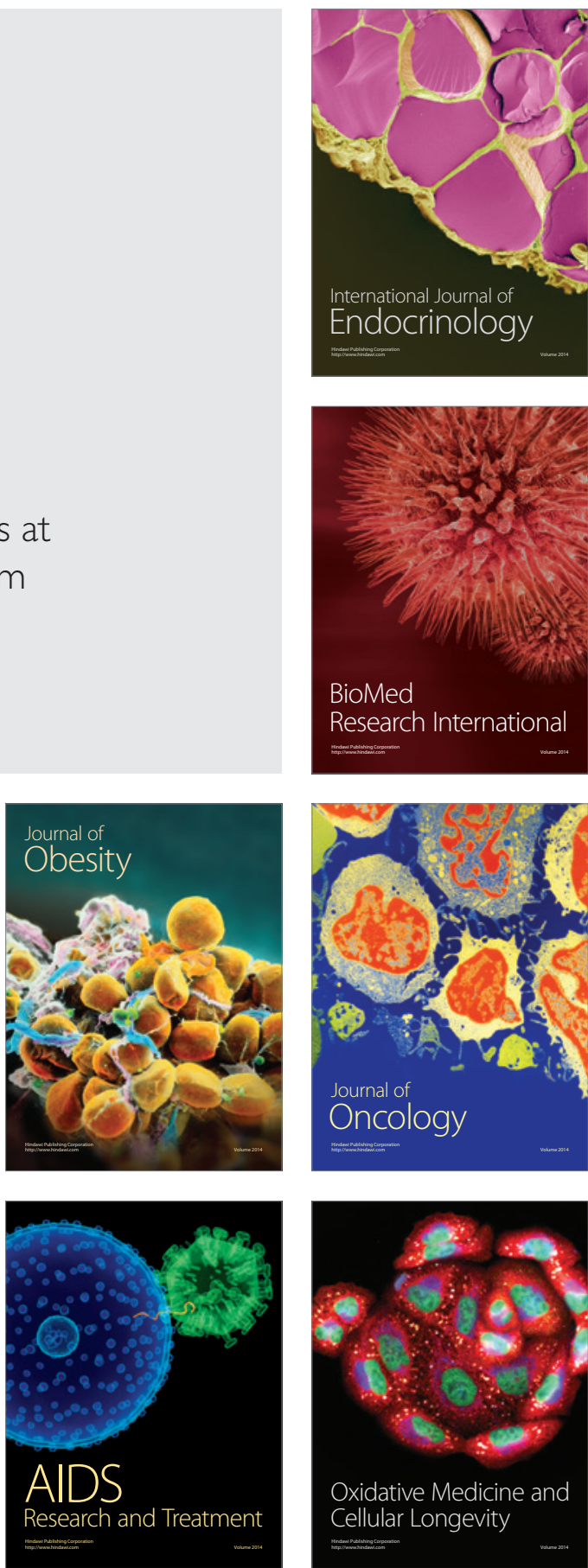